\title{
Regulation of the SNARE-interacting protein Munc18c tyrosine phosphorylation in adipocytes by protein-tyrosine phosphatase $1 \mathrm{~B}$
}

\author{
Jesse Bakke ${ }^{1 \dagger}$, Ahmed Bettaieb ${ }^{1 \dagger}$, Naoto Nagata ${ }^{1}$, Kosuke Matsuo ${ }^{1}$ and Fawaz G Haj ${ }^{1,2,3^{*}}$
}

\begin{abstract}
Background: Protein-tyrosine phosphatase 1B (PTP1B) is a physiological regulator of insulin signaling and adiposity and is a drug target for the treatment of obesity and diabetes. The molecular mechanisms underlying PTP1B metabolic actions require additional investigation.

Results: Herein, we identify Munc18c as a novel PTP1B substrate in adipocytes and in vivo. We demonstrate nutritional regulation of Munc18c in adipose tissue revealing decreased expression upon high fat feeding. In addition, PTP1B deficiency leads to elevated Munc18c tyrosine phosphorylation and dissociation from syntaxin4. At the molecular level, we identify Munc18c Tyr ${ }^{218 / 219}$ and $\mathrm{Tyr}^{521}$ as key residues that mediate Munc18c interaction with PTP1B. Further, we uncover an essential role of Munc18c total tyrosine phosphorylation in general, and Tyr 218/219 $^{2}$ and $\mathrm{Tyr}^{521}$ in particular, in regulating its interactions and glucose uptake in adipocytes.

Conclusion: In conclusion, our findings identify PTP1B as the first known tyrosine phosphatase for Munc18c and a regulator of its phosphorylation and function in adipocytes.
\end{abstract}

Keywords: PTP1B, Munc18c, SNARE complex, Adipocytes, Glucose

\section{Background}

Glucose homeostasis is tightly controlled through the regulated balance of absorption from the intestine, production from the liver and uptake by peripheral tissues. Most postprandial glucose uptake in peripheral tissues occurs in muscle and fat. Insulin-stimulated glucose uptake in these tissues is mediated by translocation of vesicles containing the glucose transporter GLUT4 from intracellular stores to the cell periphery and subsequent fusion with the plasma membrane (PM) resulting in the externalization of GLUT4 $[1,2]$. Fusion of GLUT4 vesicles with the PM is mediated by soluble $\mathrm{N}$-ethylmaleimide-sensitive factor attachment protein receptor (SNARE) complex that consists of synaptosomal-associated protein (SNAP23), syntaxin 4 and vesicle-associated membrane protein 2 (VAMP2)

\footnotetext{
*Correspondence: fghaj@ucdavis.edu

${ }^{\dagger}$ Equal contributors

'Nutrition Department, University of California Davis, One Shields Ave, 3135 Meyer Hall, Davis, CA 95616, USA

${ }^{2}$ Department of Internal Medicine, University of California Davis, Sacramento, CA 95817, USA

Full list of author information is available at the end of the article
}

[3-5]. SNARE complexes are strictly regulated to ensure that trafficking occurs with precise spatial and temporal coordinates.

Sec1/Munc18 (SM) proteins are essential regulators of SNARE-mediated vesicle budding and fusion events. SM proteins are conserved in Saccharomyces cerevisiae (Sec1), Caenorhabditis elegans (Unc18) and mammalian systems (Munc18). Mammalian cells express three isoforms (a, b and c) of Munc18 from the SM protein family and are largely localized to the PM [6,7]. Munc18-1 (also known as Munc18a) is expressed predominantly in neuronal tissues and plays an important role in neurotransmitter release $[8,9]$. Munc18b and Munc18c are ubiquitously expressed [7], though only Munc18c is implicated in the regulation of GLUT4 translocation in adipocytes. 3T3-L1 adipocytes use solely the Munc18c-syntaxin4 pair to regulate insulin-stimulated GLUT4 vesicle exocytosis [10,11]. Studies of Munc18c overexpression in adipocytes or using peptides that inhibit its binding to syntaxin4 reveal an inhibitory role of Munc18c in insulin-stimulated GLUT4 translocation to the PM [11-13]. In line with these

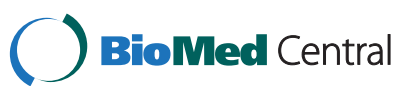

(c) 2013 Bakke et al.; licensee BioMed Central Ltd. This is an Open Access article distributed under the terms of the Creative Commons Attribution License (http://creativecommons.org/licenses/by/2.0), which permits unrestricted use, distribution, and reproduction in any medium, provided the original work is properly cited. 
findings, adipocytes from Munc18c knockout (KO) mice exhibit increased sensitivity to insulin-stimulated GLUT4 externalization and suggest that Munc18c-syntaxin4 interaction should be disrupted for docking/fusion to proceed [14]. Of note, Munc18c undergoes stimulusinduced tyrosine phosphorylation at Tyr521 to dissociate from syntaxin4 in 3T3-L1 adipocytes [15]. Moreover, the insulin receptor (IR) was identified as a kinase that phosphorylates Munc18c at Tyr521, thereby linking insulin signaling directly to SNARE exocytosis $[15,16]$. Thus, tyrosine phosphorylation of Munc18c is a regulator of its interactions and function; however, the phosphatase(s) that regulates Munc18c phosphorylation remains unidentified.

Protein-tyrosine phosphatase 1B (PTP1B) is a ubiquitously expressed non-receptor tyrosine-specific phosphatase that is localized on the cytoplasmic face of the endoplasmic reticulum (ER) [17-19]. PTP1B is a physiological regulator of glucose homeostasis and energy balance. Specifically, whole-body PTP1B knockout (KO) mice are hypersensitive to insulin, lean and resistant to high fat diet (HFD)-induced obesity [20,21]. Mice with tissue specific PTP1B deletion in the liver and muscle exhibit improved glucose homeostasis independent of body weight [22-24], while mice with neuronal deletion exhibit decreased body weight [25]. However, the role of PTP1B in adipocytes is unresolved with studies demonstrating detrimental or beneficial effects of adipose PTP1B deficiency on body mass and insulin sensitivity $[25,26]$. The salutary effects of PTP1B deficiency on obesity and diabetes have focused attention on this phosphatase as a potential therapeutic target. In this study, we identify Munc18c as a novel PTP1B substrate in adipocytes and demonstrate regulation of Munc18c tyrosine phosphorylation and function by PTP1B.

\section{Results}

PTP1B regulates Munc18c tyrosine phosphorylation

The adipose tissue is a regulator of systemic glucose homeostasis and energy balance [27]. There are two major types of adipose tissues in mammals, white and brown. White adipose tissue (WAT) is the main site for triglyceride storage, whereas brown adipose tissue (BAT) plays a role in the defense against cold and has emerging anti-obesity properties [28,29]. To gain insights into the molecular mechanisms underlying PTP1B metabolic actions, we utilized mass spectroscopy and substrate-trapping to determine novel PTP1B substrates in adipocytes [30]. These studies identified known PTP1B substrates indicating the validity of the approach but also uncovered several novel putative substrates including Munc18c. Initially, we examined Munc18c expression in differentiating adipocytes and in adipose tissue depots. Immunoblots of Munc18c in brown [31] and white (3T3-L1) adipose cell lines revealed increased Munc18c expression upon adipocyte differentiation (Figure 1A). In addition, we determined the effect of high fat feeding on Munc18c expression in adipose tissue depots. Mice were fed regular chow diet or HFD and then sacrificed after 3, 7, and 11 weeks. Immunoblots revealed significant decrease in Munc18c expression in mice fed HFD compared with those fed regular chow in all examined adipose depots (Figure 1B-G). Of note, Munc18c cognate syntaxin, syntaxin 4 demonstrated comparable expression pattern increasing in adipocytes during differentiation and decreasing in adipose tissue depots upon high fat feeding (Figure 1). These findings demonstrate regulated expression of Munc18c in adipose tissue depots.

If Munc18c is a PTP1B substrate then PTP1B deficiency should lead to increased Munc18c tyrosine phopshorylation. To test this, we utilized PTP1B KO adipocytes [31] that are reconstituted with PTP1B wild type (WT) or the substrate-trapping mutant D181A (D/A) that retains substrate binding but is catalytically impaired [32]. Munc18c was immunoprecipitated from starved and insulin-stimulated (10 minutes) KO, WT and D/A adipocytes then immunoblotted using anti-phosphotyrosine antibodies (Figure 2A). In line with previous studies $[15,33,34]$, insulin stimulation increased Munc18c tyrosine phosphorylation in WT adipocytes. Importantly, basal and insulin-stimulated Munc18c tyrosine phosphorylation was significantly elevated in $\mathrm{KO}$ and D/A compared with WT adipocytes. To evaluate if adipose PTP1B deficiency in vivo modulates Munc18c tyrosine phosphorylation, we determined Munc18c phosphorylation in the subcutaneous adipose depot of control $(\mathrm{fl} / \mathrm{fl})$ and adipose-specific PTP1B KO mice. Insulin treatment led to increased Munc18c tyrosine phosphorylation in WT mice compared with basal (Figure 2B). Further, adipose-specific PTP1B $\mathrm{KO}$ mice exhibited increased basal and insulin-stimulated Munc18c tyrosine phosphorylation compared with control mice (Figure 2B). Since Munc18c tyrosine phosphorylation disrupts its interaction with syntaxin4 [15,16,33,34], we examined if PTP1B deficiency-induced increase in Munc18c tyrosine phosphorylation results in attenuated interaction with syntaxin 4 . To that end, Munc18c was immunoprecipitated from starved and insulin-stimulated WT and KO adipocytes then immunoblotted for syntaxin4 (Figure 2C). Indeed, insulin stimulation attenuated Munc18c-syntaxin4 interaction in WT adipocytes compared with basal. Further, basal and insulin-stimulated Munc18c-syntaxin4 co-association was lower in $\mathrm{KO}$ compared with WT adipocytes consistent with elevated Munc18c phosphorylation in KO adipocytes. Together, these data demonstrate that PTP1B deficiency in adipocytes and in vivo leads to increased Munc18c tyrosine phosphorylation. 
A

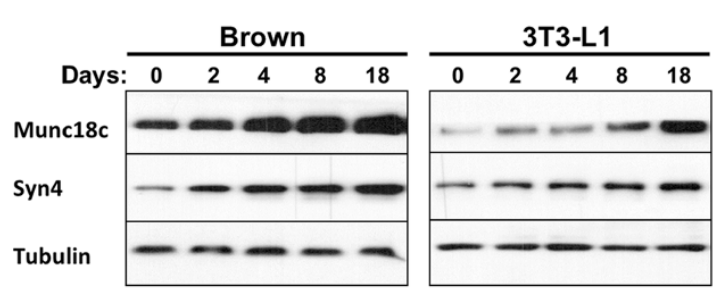

C

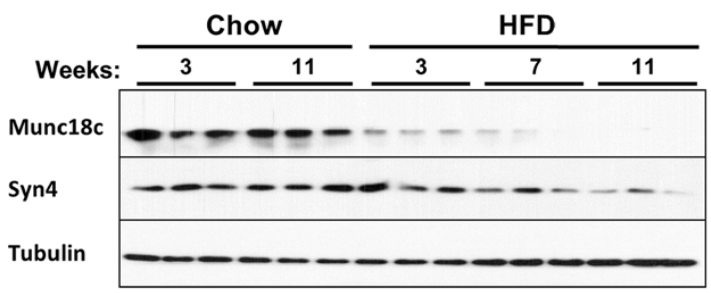

S.Q.

E

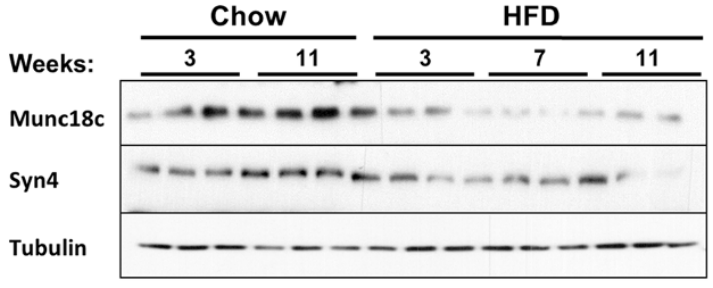

Mes.
B

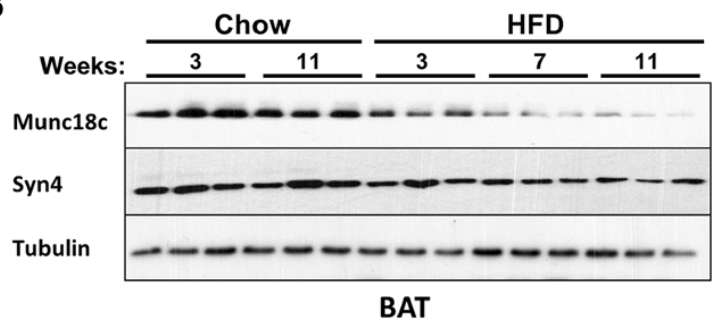

D

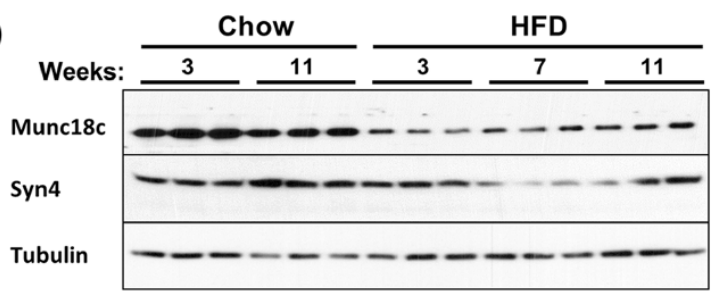

Epi.

$\mathbf{F}$

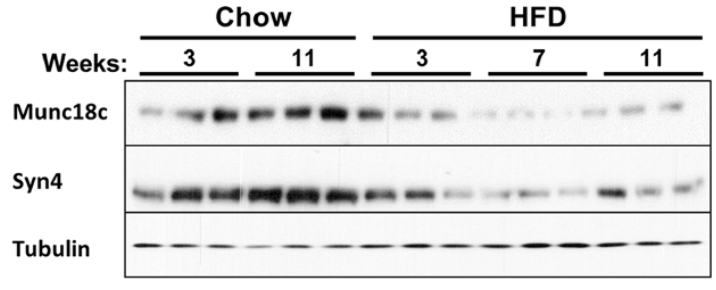

Ret.

G

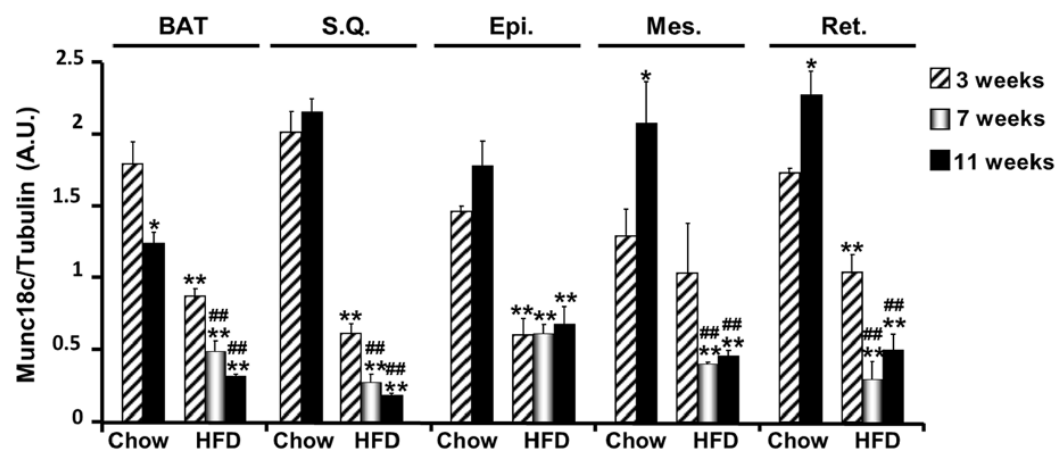

H

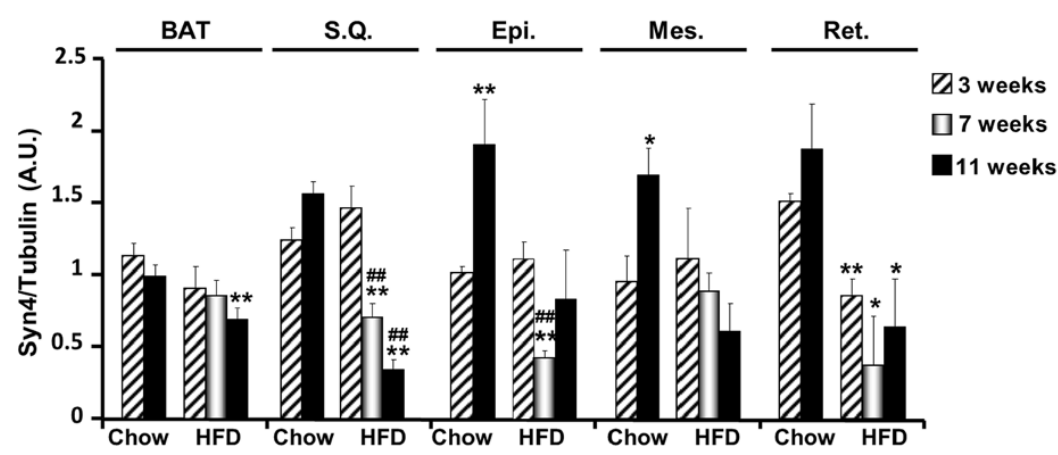

Figure 1 (See legend on next page.) 
(See figure on previous page.)

Figure 1 Munc18c expression in adipocytes and adipose tissue depots. A) Immunoblots of Munc18c, syntaxin4 and Tubulin in lysates of brown and white (3T3-L1) adipocytes at different stages of differentiation. B-F) Immunoblots of Munc18C, syntaxin4 and Tubulin in lysates of brown (BAT), subcutaneous (S.Q.), epididymal (Epi.), mesenchymal (Mes.), and retroperitoneal (Ret.) adipose depots of mice fed regular chow or HFD for the indicated times. Each lane represents a sample from a separate animal. Bar graphs represent normalized data for Munc18c (G) and syntaxin4 $(\mathbf{H})$ expression normalized to Tubulin and presented as means \pm SEM. $\left({ }^{*} ; P \leq 0.05,{ }^{* *} ; P \leq 0.01\right)$ indicate significant difference, in each adipose depot, between all groups versus mice fed regular chow for 3 weeks, and (\#; $P \leq 0.05$, \#\#; $P \leq 0.01$ ) indicate significant difference between mice fed HFD for 7 and 11 weeks versus mice fed HFD for 3 weeks.

\section{Munc18c is a novel PTP1B substrate}

The elevated Munc18c tyrosine phosphorylation upon PTP1B deficiency promoted us to test whether Munc18c is a direct substrate of PTP1B. Wild type PTP1B has a high catalytic constant rendering its interaction with substrates difficult to detect [35]. However, steady-state interaction of PTP1B with its substrates can be enhanced using the substrate-trapping mutant that forms stable complexes with tyrosine-phosphorylated substrates and has been successfully utilized to identify PTP1B substrates [19,32,36-38]. PTP1B was immunoprecipitated from $\mathrm{KO}$ and $\mathrm{D} / \mathrm{A}$ adipocytes and co-association with Munc18c was determined. As expected, no association was detected in $\mathrm{KO}$ adipocytes, but co-association was observed in D/A adipocytes under basal conditions and was significantly enhanced upon insulin stimulation (Figure 3A). To further investigate the mechanism underlying Munc18c-PTP1B interaction, we utilized lentiviral shRNA to generate 3T3-L1 preadipocytes with stable knockdown (KD) of
Munc18c. Knockdown cells were reconstituted with wild type Munc18c (R), and tyrosine (Y)-to-phenylalanine (F) mutants $\mathrm{Y}^{218 / 219} \mathrm{~F}$ and $\mathrm{Y}^{521} \mathrm{~F}$ (Figure 3B). Munc18c Tyr218/219 and Tyr521 sites were specifically evaluated for several reasons: (a) these sites are conserved in many species (Figure 3C), (b) both sites are identified biochemically as important for Munc18c-syntaxin4 binding [34], (c) Munc18c undergoes stimulus-induced tyrosine phosphorylation at Tyr219 in islet $\beta$-cells and Tyr521 in 3T3L1 adipocytes [15,33,34], (d) IR phosphorylates Munc18c at Tyr521 in 3T3-L1 adipocytes [15,16], and (e) the amino acid sequence flanking Tyr218/219 is similar to E/D-pY$\mathrm{pY}-\mathrm{R} / \mathrm{K}$ which has been reported as important for optimal substrate recognition by $\mathrm{PTP} 1 \mathrm{~B}$ (but is not a requirement) [39]. PTP1B WT and D/A were transiently expressed in WT adipocytes and in adipocytes with Munc18c knockdown reconstituted with Munc18c $\mathrm{Y}^{218 / 219} \mathrm{~F}$ and $\mathrm{Y}^{521} \mathrm{~F}$ mutants, then co-association with Munc18c was determined (Figure 3D). We did not expect co-association
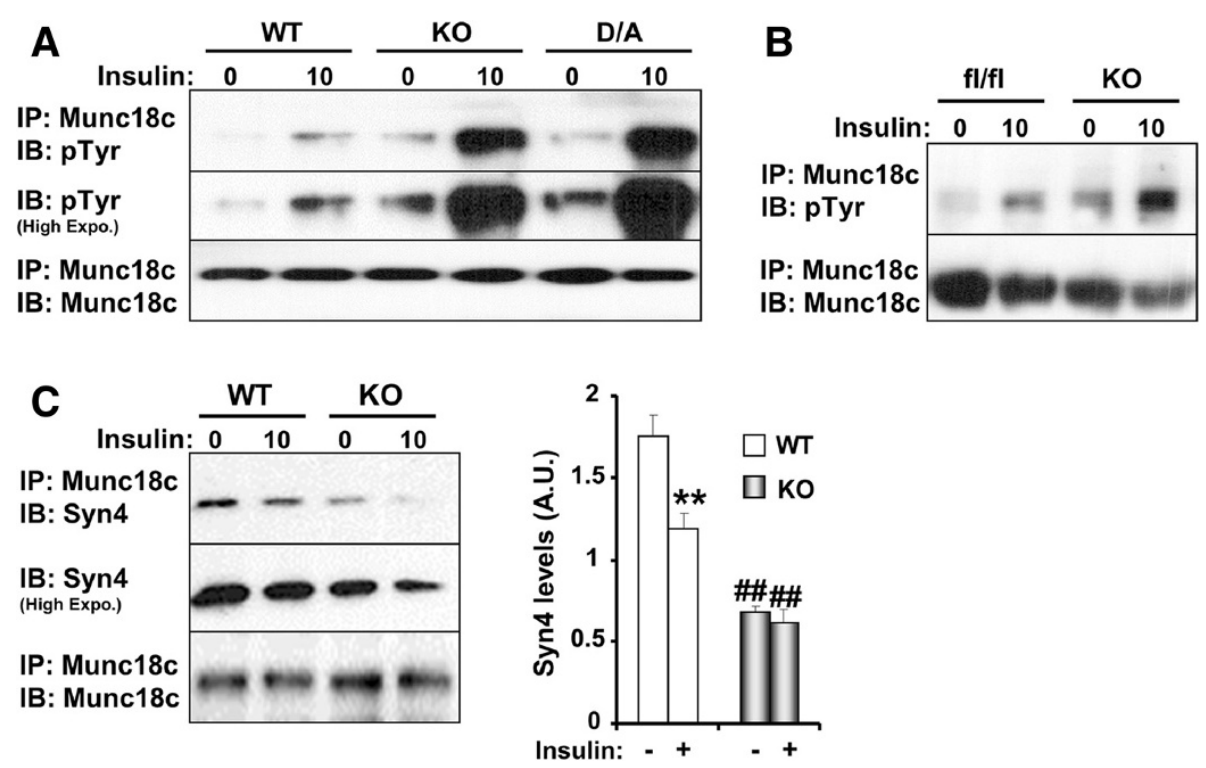

Figure 2 PTP1B regulates Munc18c tyrosine phosphorylation. A) Munc18c was immunoprecipitated from lysates of PTP1B KO adipocytes and KO adipocytes reconstituted with PTP1B WT and D/A at basal and insulin-stimulated conditions then immunoblotted using antibodies for phosphotyrosine and Munc18c. B) Munc18c was immunoprecipitated from subcutaneous adipose tissue of control (fl/fl) and adipose-specific PTP1B KO fed HFD then immunoblotted using antibodies for phosphotyrosine and Munc18c. C) Munc18c was immunoprecipitated from PTP1B $\mathrm{KO}$ adipocytes and $\mathrm{KO}$ adipocytes reconstituted with $\mathrm{WT}$ at basal and insulin-stimulated conditions then immunoblotted using antibodies for syntaxin4 and Munc18c. Bar graph represents normalized data presented as means \pm SEM. (**; $P \leq 0.01)$ indicates significant difference between insulin treated and non-treated cells, and (\#\#; $P \leq 0.01)$ indicates significant difference between $W T$ and $K O$ cells for the corresponding treatment. 
A

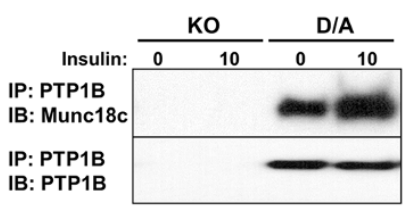

C

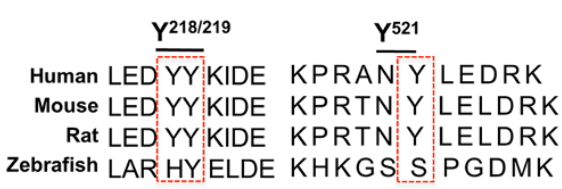

B

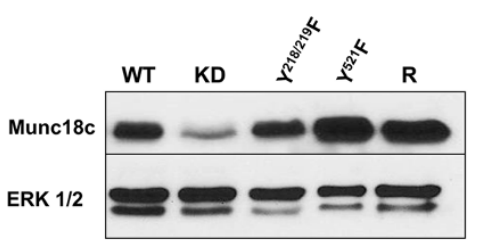

D

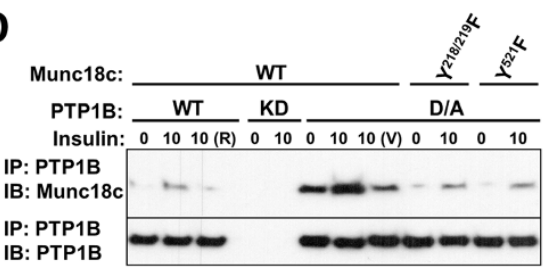

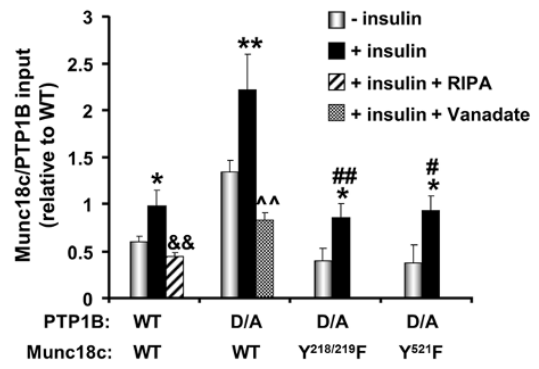

Figure 3 Munc18c is a PTP1B substrate. A) PTP1B was immunoprecipitated from lysates of PTP1B KO adipocytes and KO adipocytes reconstituted with PTP1B D/A at basal and insulin-stimulated conditions then immunoblotted using antibodies for Munc18c and PTP1B. B) Munc18c knockdown (KD) cells were reconstituted with Munc18c wild type (R) and $Y / F$ mutants $\left(Y^{218 / 219} \mathrm{~F}\right.$ and $\left.\mathrm{Y}^{521} \mathrm{~F}\right)$. Lysates were immunoblotted for Munc18c and Erk1/2. C) Sequences were aligned relative to amino acids Tyr $^{218 / 219}$ and Tyr ${ }^{521}$ of mouse Munc18c. The boxed region denotes the location of amino acids $\mathrm{Tyr}^{218 / 219}$ and Tyr ${ }^{521}$ across species. D) 3T3-L1 wild type (WT) and Munc18c knockdown cells (reconstituted with Y/F mutants) were transiently transfected with PTP1B WT and D/A. PTP1B was immunoprecipitated using FG6 antibodies from starved and insulin-stimulated cells lysed in NP40 or RIPA (R), resolved using SDS-PAGE then immunoblotted using antibodies for Munc18c and PTP1B. Bar graph represents Munc18c levels in PTP1B immunoprecipitates normalized to level of PTP1B and presented as means \pm SEM. $\left(^{*} ; P \leq 0.05, *^{*} ; P \leq 0.01\right)$ indicate significant difference between insulin stimulated and non-stimulated cells, (\#; $P \leq 0.05, \# \# ; P \leq 0.01)$ indicate significant difference between Munc18c Y/F mutants and Munc18c WT insulin stimulated D/A cells, $(\& \& ; P \leq 0.01)$ indicates significant difference between RIPA-treated and non-treated insulin stimulated $W T$ cells, and $(\wedge \wedge ; P \leq 0.01)$ indicates significant difference between vanadate-treated and non-treated insulin stimulated D/A cells.

between PTP1B WT and Munc18c given the transient nature of the interaction. However, modest co-immu noprecipitation was observed upon insulin stimulation (Figure 3D), but is likely indirect and probably due to the presence of both proteins in a large signaling complex. Indeed, lysis of cells using the stringent lysis buffer RIPA (R) disrupted PTP1B WT-Munc18c co-association (Figure 3D, lane 3). As expected, no co-association was observed in cells with PTP1B knockdown (Figure 3D, lanes 4, 5). Consistent with the proposed hypothesis, co-association of endogenous Munc18c and PTP1B D/A was detected under basal conditions and was significantly enhanced upon insulin stimulation (Figure 3D). Importantly, treatment with pervanadate $(\mathrm{V})$, a strong inhibitor of tyrosine phosphatases which oxidizes the essential cysteinyl residue in the catalytic center of the enzymes [40], disrupted Munc18cPTP1B D/A interaction (Figure 3C, lane 8). This indicated that the association is consistent with enzyme-substrate interaction that is mediated by the active site cysteinyl residue of PTP1B. Of note, $\mathrm{Y}^{218 / 219} \mathrm{~F}$ and $\mathrm{Y}^{521} \mathrm{~F}$ mutations significantly attenuated Munc18c association with PTP1B D/A (Figure 3C). Together, these data demonstrate that Munc18c is a direct substrate of PTP1B and that $\mathrm{Tyr}^{218 /}$ ${ }^{219}$ and $\mathrm{Tyr}^{521}$ are mediators of the association.

\section{Munc18c tyrosine phosphorylation regulates its binding to syntaxin 4}

We investigated the role of Munc18c total and $\mathrm{Tyr}^{218 / 219}$ and $\mathrm{Tyr}^{521}$ phosphorylation in Munc18c interactions and the insulin-stimulated SNARE-mediated delivery of GLUT4 to the plasma membrane. Initially, we determined Munc18c total tyrosine phosphorylation in 3T3-L1 adipocytes (WT) and in adipocytes with knockdown (KD) and reconstituted expression of Munc18c $\left(R, Y^{218 / 219} \mathrm{~F}\right.$ and $\mathrm{Y}^{521} \mathrm{~F}$ ) under basal and insulin-stimulated conditions. Munc18c was immunoprecipitated from NP-40 lysed 
adipocytes then tyrosine phosphorylation determined using anti-phosphotyrosine antibodies (Figure 4A). WT adipocytes exhibited a low but detectable level of Munc18c tyrosine phosphorylation under basal conditions and this was significantly increased upon insulin stimulation. As expected, Munc18c phosphorylation was attenuated in knockdown cells, while reconstitution with Munc18c (R) restored phosphorylation to control (WT) levels. Of note, $\mathrm{Y}^{218 / 219} \mathrm{~F}$ and $\mathrm{Y}^{521} \mathrm{~F}$ adipocytes exhibited impaired insulin-stimulated Munc18c tyrosine phosphorylation (Figure 4A). To further demonstrate regulation of PTP1B/Munc18c co-association by tyrosine phosphorylation, Munc18c immunoprecipitates were immunoblotted for PTP1B. In line with Munc18c tyrosine phosphorylation, insulin significantly enhanced Munc18c co-as sociation with PTP1B and this was significantly attenuated in $\mathrm{Y}^{218 / 219} \mathrm{~F}$ and $\mathrm{Y}^{521} \mathrm{~F}$ adipocytes (Figure $4 \mathrm{~A}$ ). Next, we sought to determine the effects of Munc18c phosphorylation on its interactions with syntaxin4, so Munc18c immunoprecipitates were immunoblotted for syntaxin4. WT and reconstituted (R) adipocytes exhibited robust association of syntaxin4 and Munc18c under basal conditions and this was disrupted upon insulin stimulation in line with increased Munc18c tyrosine phosphorylation. Interestingly, whereas syntaxin4 associated with Munc18c under basal conditions in $\mathrm{Y}^{218 / 219} \mathrm{~F}$ and $\mathrm{Y}^{521} \mathrm{~F}$ adipocytes, it failed to dissociate upon insulin stimulation (Figure 4A). Similar binding pattern was observed in reciprocal coimmunoprecipitation experiments where syntaxin4 was immunoprecipitated and binding of Munc18c determined (Figure 4B). Importantly, dissociation of Munc18c from syntaxin4 enables binding of GLUT4. Indeed, WT and reconstituted (R) adipocytes exhibited robust insulinstimulated syntaxin4-GLUT4 association and this was impaired in $\mathrm{Y}^{218 / 219} \mathrm{~F}$ and $\mathrm{Y}^{521} \mathrm{~F}$ adipocytes (Figure 4B). It is important to note that syntaxin4-GLUT4 association is in line with deoxyglucose uptake in these adipocytes (see Figure 5C). Together, these findings establish an essential role of tyrosine phosphorylation in general, and $\mathrm{Tyr}^{218 / 219}$ and $\mathrm{Tyr}^{521}$ in particular, in regulating Munc $18 \mathrm{c}$ associations and demonstrate that insulin-induced tyrosine phopshorylation triggers Munc18c dissociation from syntaxin4 thereby facilitating SNARE-mediated delivery of GLUT4 to the plasma membrane.
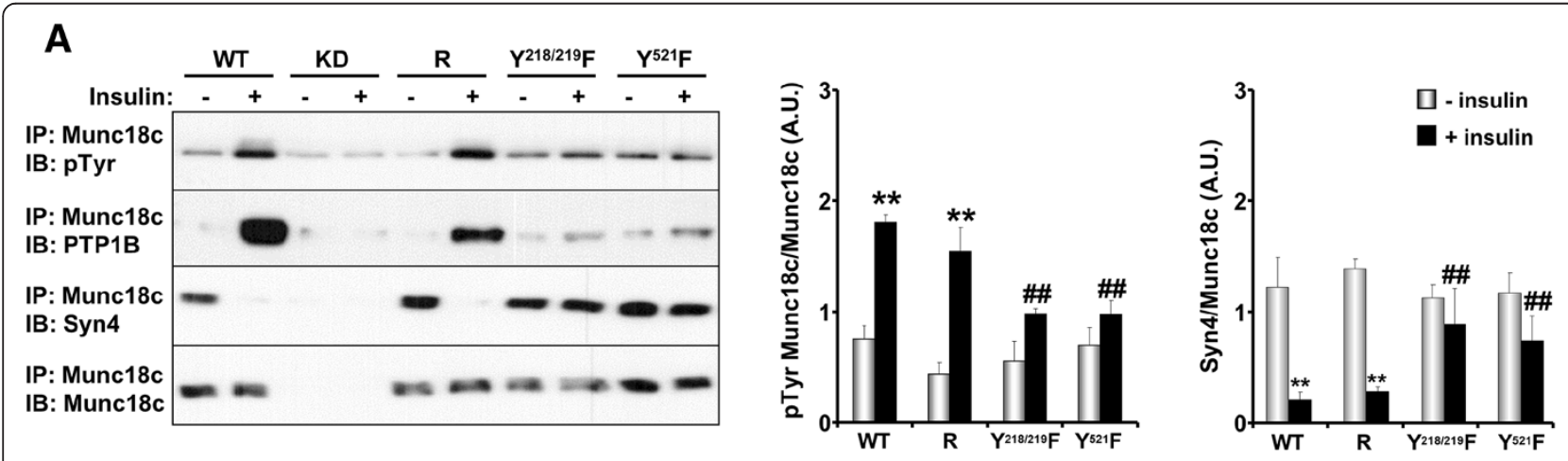

B
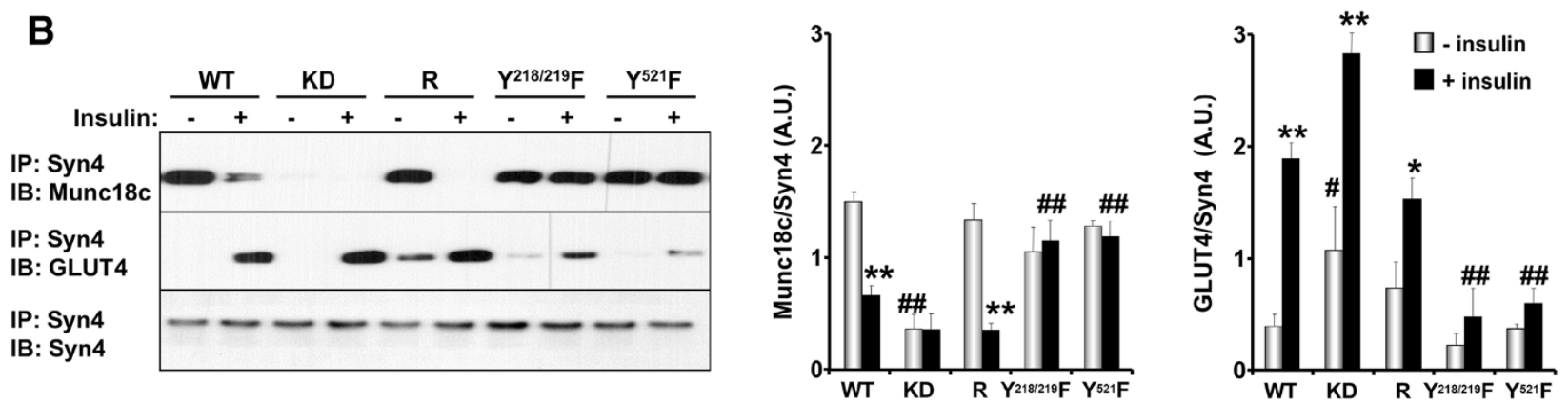

Figure 4 Tyrosine phosphorylation of Munc18c regulates its binding to syntaxin4 and PTP1B. A) Munc18c was immunoprecipitated from lysates of wild type adipocytes and adipocytes with knockdown and reconstituted expression of Munc18c (R and Y/F mutants) at basal and insulinstimulated conditions, then immunoblotted using antibodies for phosphotyrosine, PTP1B, Syn4 and Munc18c. Bar graphs represent normalized data for tyrosine phosphorylated Munc18c/Munc18c and Syn4/Munc18c and presented as means \pm SEM. B) Syn4 was immunoprecipitated from lysates of WT adipocytes and adipocytes with knockdown and reconstituted expression of Munc18c (R and Y/F mutants) at basal and insulin-stimulated conditions, then immunoblotted using antibodies for Munc18c, Glut4 and Syn4. Bar graphs represent normalized data for Munc18c/Syn4 and Glut4/ Syn4 and presented as means \pm SEM. (*; $\left.P \leq 0.05,{ }^{* *} ; P \leq 0.01\right)$ indicate significant difference between insulin stimulated and non-stimulated cells, and (\#; $P \leq 0.05, \# \# ; P \leq 0.01$ ) indicate significant difference between different cells versus WT for the corresponding treatment. 


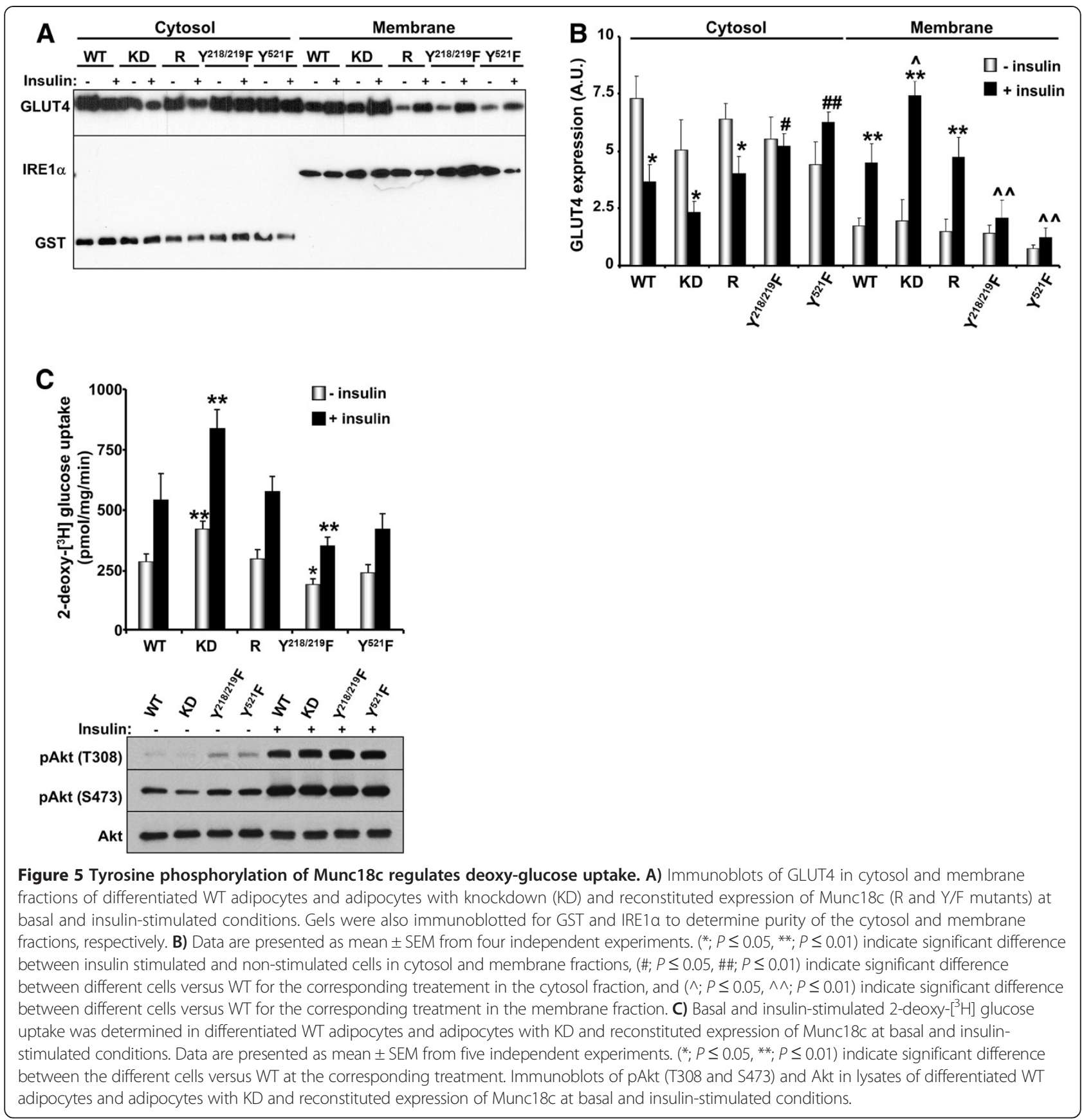

\section{Munc18c phosphorylation is required for insulin-}

\section{stimulated glucose uptake}

To determine the functional requirements for Munc $18 \mathrm{c}$ total and site-specific tyrosine phosphorylation in GLUT4 vesicle exocytosis, we evaluated GLUT4 subcellular distribution and 2-deoxy-glucose uptake in differentiated adipocytes. Differentiated Munc18c knockdown and reconstituted adipocytes exhibited comparable triglyceride content (determined using oil Red $\mathrm{O}$ staining; data not shown) suggesting that Munc18c does not significantly affect adipogenesis in vitro, in line with previous observations [14]. Fractionation of adipocytes revealed increased GLUT4 in membrane fraction of knockdown compared with WT adipocytes (Figure 5A, B). Notably, GLUT4 was significantly decreased in membrane fraction of $\mathrm{Y}^{218 / 219} \mathrm{~F}$ and $\mathrm{Y}^{521} \mathrm{~F}$ adipocytes compared with WT (Figure 5A, B). Further, we evaluated basal and insulin-stimulated 2-deoxy-glucose uptake in adipocytes. Insulin stimulation led to clear increase in glucose uptake in control adipocytes (Figure 5C). Importantly, knockdown adipocytes exhibited increased basal and insulin-stimulated glucose uptake compared with WT. This finding is in line 
with a previous report that demonstrates increased sensitivity to insulin-stimulated GLUT4 externalization in adipocytes of Munc18c knockout mice [14]. In addition, reconstituted ( $\mathrm{R}$ ) adipocytes exhibited comparable basal and insulin-stimulated glucose uptake to WT adipocytes, indicating that the observed effects in knockdown cells are directly due to Munc18c deficiency. On the other hand, basal and insulin-stimulated glucose uptake was attenuated in $\mathrm{Y}^{218 / 219} \mathrm{~F}$ adipocytes and exhibited a trend for attenuation in $\mathrm{Y}^{521} \mathrm{~F}$ adipocytes compared with WT (Figure 5C). Finally, Akt activation (determined by phosphorylation at T308 and S473) was comparable between adipocytes. Together, these data demonstrate a requirement for Munc18c tyrosine phosphorylation in insulin-stimulated glucose uptake in adipocytes (Figure 6).

\section{Discussion}

Munc18 proteins are essential regulators of SNAREmediated vesicle budding and fusion events, and are conserved from yeast to mammals. In this study, we demonstrated nutritional regulation of Munc18c isoform in adipose tissue in mice. In addition, we identified Munc18c as a novel PTP1B substrate in adipocytes and in vivo and uncovered Munc18c $\mathrm{Tyr}^{218 / 219}$ and $\mathrm{Tyr}^{521}$ as key residues that mediate the association. Further, we established an essential role of Munc18c tyrosine phosphorylation in general, and $\mathrm{Tyr}^{218 / 219}$ and $\mathrm{Tyr}^{521}$ in particular, in regulating Munc18c interactions and glucose uptake in adipocytes. Together, these findings identify PTP1B as the first known tyrosine phosphatase for Munc18c and as an important regulator of its phosphorylation and function in adipocytes.

Munc18c expression is regulated in the adipose tissue and chronic high fat feeding in mice leads to decreased Munc18c protein. Expression of the cognate syntaxin, syntaxin 4 is also decreased in adipose tissue upon high fat feeding consistent with tight control of Munc18c/ syntaxin 4 interaction and coordinate regulation of these proteins. The current findings are in line with a recent report demonstrating down regulation of Munc18c

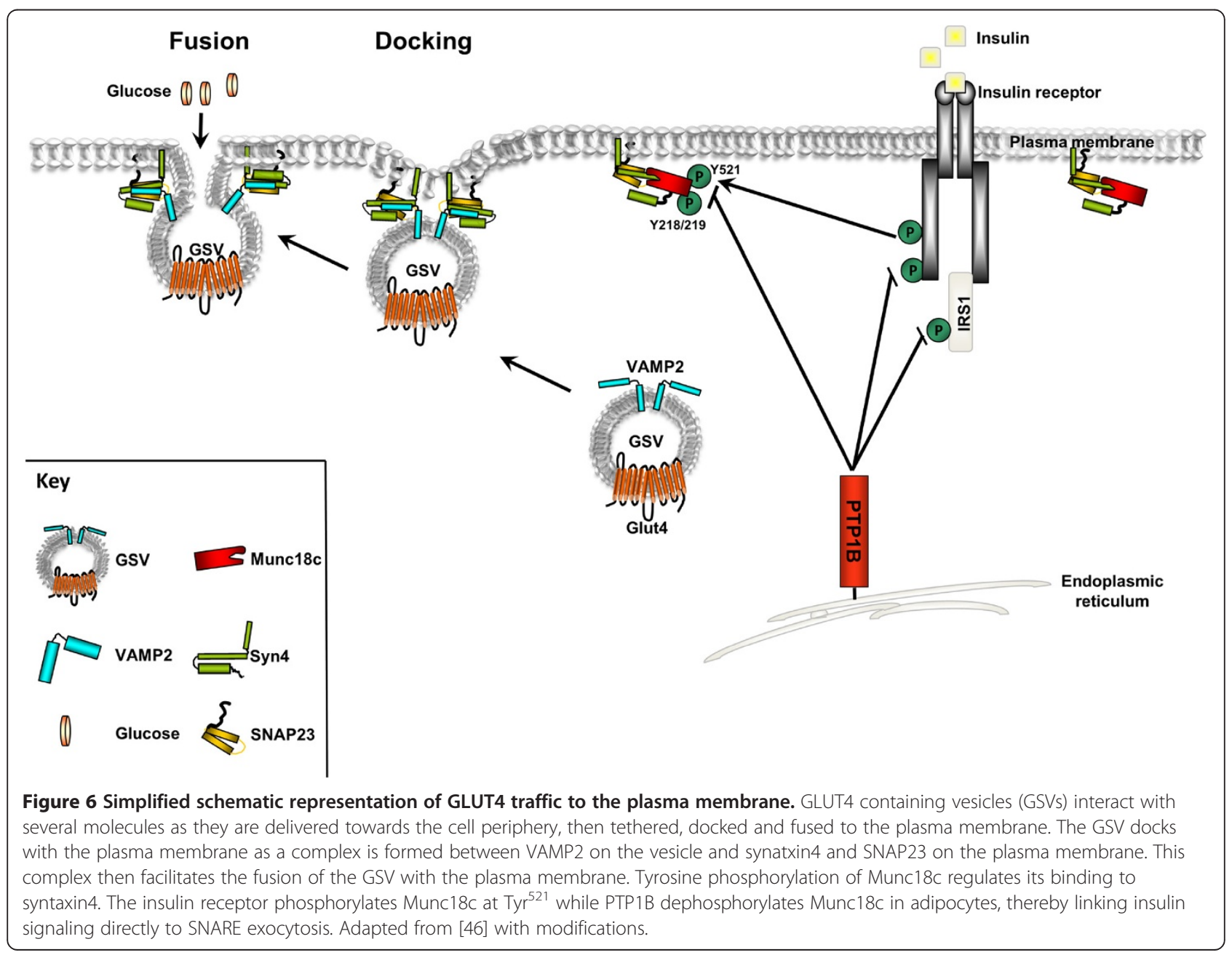


protein expression in visceral and subcutaneous adipose tissue depots of morbidly obese human subjects [41]. It is not clear if decreased Munc18c expression in overweight/obese rodents and humans is directly attributed to obesity or other factor(s) such as elevated proinflammatory response to HFD. We speculate that down regulation of Munc18c presents a mode of regulation that may serve as a compensatory mechanism to facilitate GLUT4 translocation and modulate insulin action. Indeed, Munc18c expression decreases after prolonged fasting in skeletal muscle of lean and obese subjects concurrently with reduced insulin action [42]. Understanding the different tiers of Munc18c regulation, such as expression and tyrosine phosphorylation as presented herein, will yield insights into GLUT4 trafficking and possible modalities to increase glucose transport.

Munc18c is a novel PTP1B substrate as evidenced by several supporting observations. Mass spectrometry of adipocytes expressing the substrate-trapping PTP1B mutant identified Munc18c as a PTP1B-interacting protein. In addition, adipocytes and adipose tissue lacking PTP1B exhibited increased Munc18c tyrosine phosphorylation. Moreover, substrate trapping demonstrated direct association between Munc18c and PTP1B D/A. Notably, pervanadate treatment disrupted Munc18c-PTP1B D/A association indicating that it is consistent with direct enzyme-substrate interaction that is mediated by the PTP1B active site. At the molecular level we identified Munc18c $\mathrm{Tyr}^{218 / 219}$ and $\mathrm{Tyr}^{521}$ as key residues that mediate the association with PTP1B. It is important to note that structurally these tyrosine residues are predicted to be in close proximity [16]. In addition, $\mathrm{Tyr}^{521}$ is in the disordered region of Munc18c that is notable for posttranslational modifications and conformation changes [16]. Importantly, $\mathrm{Tyr}^{521}$ was recently identified as the residue that is phosphorylated by IR upon insulin stimulation $[15,16]$. Therefore, Munc18c tyrosine phosphorylation is regulated, at least in large part, by the opposing actions of IR and PTP1B with precise spatial and temporal coordinates. In one scenario, insulin stimulation leads to IR activation and phosphorylation of Munc18c $\mathrm{Tyr}^{521}$ allowing for signal propagation that is then followed by dephosphorylation by PTP1B (Figure 6). Indeed, insulin stimulation leads to reversible oxidation of PTP1B at its active site and transient attenuation of its enzymatic activity [43]. One function of insulin-induced oxidation is transient inactivation of PTP1B, which usually exerts inhibitory constraint on the system, to initiate a signaling response to the stimulus. It is important to note that additional protein-tyrosine phosphatase(s) may also regulate Munc18c phosphorylation. Further, Munc18c is expressed in additional metabolic cells/tissues such as pancreatic $\beta$-cells where PTP1B is also expressed
[44], and additional studies are required to determine if PTP1B regulates Munc18c (or other isoforms) in these cells. At any rate, the current findings are the first to identify a protein-tyrosine phosphatase that directly regulates Munc18c tyrosine phosphorylation and function in adipocytes.

The current findings demonstrate that Munc18c tyrosine phosphorylation regulates its interactions and are consistent with a functional requirement for Munc18c phosphorylation in glucose uptake in adipocytes. Munc18c tyrosine phosphorylation was elevated upon PTP1B deficiency (in adipocytes and in vivo) leading to concomitant decrease ( $60 \%)$ in Munc18c-syntaxin4 association. Comparable attenuation of Munc18c-syntaxin 4 association was reported in adipocytes upon insulin stimulation [33] or pervanadate treatment (i.e. PTP inhibition) [16]. In particular, mutants of the tyrosine residues $\left(\mathrm{Tyr}^{218 / 219}\right.$ and $\mathrm{Tyr}^{521}$ ) that mediate Munc18c-PTP1B interaction lacked the ability to dissociate from syntaxin4 upon insulin stimulation (Figure 4B) demonstrating the importance of these tyrosines in regulating Munc18c interactions. Importantly, we demonstrated that Munc18c association with syntaxin 4 is of functional significance. Munc18c deficiency facilitated syntaxin4-GLUT4 interaction leading to enhanced glucose uptake. On the other hand, Munc18c mutants that did not dissociate from syntaxin4 disrupted its binding to GLUT4 and consequently attenuated glucose uptake. Together, our findings demonstrate an important role for PTP1B in regulating Munc18c tyrosine phosphorylation and function. Presumably PTP1B can engage different substrate(s) in adipocytes depending on the nature of the stimulus, its magnitude and duration. Given the salutary effects of PTP1B deficiency and inhibition in obesity and diabetes additional studies are warranted to fully elucidate the substrates and signaling mechanism underlying its metabolic actions.

\section{Methods}

\section{Reagents}

Dulbecco's Modified Eagle Medium (DMEM), G418, penicillin/streptomycin, puromycin, new born calf serum (NBCS), fetal bovine serum (FBS) and trypsin were purchased from Invitrogen (Carlsbad, CA). Antibodies for human PTP1B (FG6), mouse PTP1B, and Tubulin were from Abcam (Cambridge, MA). Akt, phosphotyrosine (PY99), syntaxin4, Glutathione-S-Transferase pi 1 (GST$\pi 1)$, IRE1 $\alpha$, and GLUT4 antibodies were from Santa Cruz Biotechnology (Santa Cruz, CA). pAkt (Ser473) and pAkt (Thr308) were from Cell Signaling Technology (Beverly, MA). Munc18c antibodies were from Sigma (St. Louis, MO) and phosphotyrosine (4G10) antibodies were from Millipore (Billerica, MA). Horseradish peroxidase (HRP)conjugated secondary antibodies were from BioResources 
International (Carlsbad, CA). Unless otherwise indicated, chemicals were purchased from Sigma.

\section{Mouse studies}

Male mice on C57Bl/6 J background (Jackson Laboratories) were maintained on a 12-hour light-dark cycle and fed ad libitum. Mice were fed standard laboratory chow (Purina lab chow, \# 5001) at weaning or switched to a HFD (60\% kcal from fat, \# D12492, Research Diets) at 7 weeks of age. PTP1B-floxed $\left(\mathrm{PTP}^{\mathrm{fl}}{ }^{\mathrm{fl} / \mathrm{ll}}\right)$ mice were generated previously [25]. Adiponectin (Adipoq)-Cre mice were obtained from Dr. E. Rosen (BIDMC/Harvard University). Genotyping for the PTP1B floxed allele and presence of Cre was performed by polymerase chain reaction (PCR), using DNA extracted from tails [25,38]. At the indicated age, mice were sacrificed and adipose depots collected, frozen in liquid nitrogen then stored at $-80^{\circ} \mathrm{C}$. Mouse studies were approved by Institutional Animal Care and Use Committee at University of California Davis.

\section{Cell culture}

3T3-L1 cells were maintained in DMEM containing $25 \mathrm{mM}$ glucose, $10 \%$ bovine calf serum (BCS), $50 \mathrm{U} / \mathrm{ml}$ penicillin and $50 \mu \mathrm{g} / \mathrm{ml}$ streptomycin. Munc18c was silenced in 3T3-L1 cells by testing five different hairpins (Open Biosystems). Packaging (psPAX2) and envelope (pMD2.G) vectors (Addgene, Boston) were co-transfected, along with silencing hairpins into HEK293FT cells using Lipofectamine 2000 (Invitrogen) following manufacturer's guidelines. Lentivirus was collected and used to infect 3T3-L1 cells. Cells were selected using puromycin $(2 \mu \mathrm{g} / \mathrm{ml})$ and drug-resistant pools propagated. Cells with knockdown (KD) of Munc18c were reconstituted by transfection of wild type (WT) mouse Munc18c (Origene) and $\mathrm{Y} / \mathrm{F}\left(\mathrm{Y}^{218 / 219} \mathrm{~F}\right.$ and $\left.\mathrm{Y}^{521} \mathrm{~F}\right)$ mutants. Stable cell lines were maintained under $400 \mu \mathrm{g} / \mathrm{ml}$ G418 antibiotic selection for three weeks. To induce cell differentiation, 3T3-L1 preadipocytes were grown to confluence in culture medium containing 10\% NBCS. Confluent cells were then cultured in differentiation media containing $10 \%$ FBS, $20 \mathrm{nM}$ insulin and $1 \mathrm{nM}$ triiodothyronine [T3] for $48 \mathrm{~h}$. Adipocyte differentiation was induced by treating cells for $48 \mathrm{~h}$ in differentiation medium further supplemented with $0.5 \mu \mathrm{M}$ dexamethasone, $0.5 \mathrm{mM}$ isobutylmethylxanthine, and $0.125 \mathrm{mM}$ indomethacin (induction media). After induction, cells were cultured in differentiation medium until they exhibited a differentiated phenotype with massive accumulation of fat droplets.

\section{Biochemical analyses}

Tissues and cells were lysed in radio-immunoprecipitation assay buffer (RIPA: $10 \mathrm{mM}$ Tris- $\mathrm{HCl}, \mathrm{pH}$ 7.4, $150 \mathrm{mM}$ $\mathrm{NaCl}, 0.1 \%$ sodium dodecyl sulfate [SDS], 1\% Triton X-100,
1\% sodium deoxycholate, $5 \mathrm{mM}$ EDTA, $1 \mathrm{mM} \mathrm{NaF}$, $1 \mathrm{mM}$ sodium orthovanadate and protease inhibitors). Lysates were clarified by centrifugation at 13,000 rpm for $10 \mathrm{~min}$, and protein concentrations were determined using a bicinchoninic acid assay kit (Pierce Chemical). For substrate-trapping experiments, cells were lysed in 1\% NP40 buffer with a protease inhibitor cocktail (without sodium orthovanadate). Proteins $(500 \mu \mathrm{g})$ were immunoprecipitated with Munc18c or FG6 antibodies and immune complexes were collected on protein GSepharose beads (GE Healthcare) and washed with lysis buffer. Proteins were resolved by SDS-PAGE and transferred to PVDF membranes. Immunoblots were performed using phosphotyrosine (4G10/PY99), FG6, and Munc18c antibodies. Proteins were detected using enhanced chemiluminescence (Amersham Biosciences). Resulting immunoreactive bands were quantified using FluorChem Q Imaging software (Alpha Innotech).

For site-directed mutagenesis, tyrosine (Y) to phenylalanine (F) mutations in mouse Munc18c cDNA (origene) were generated using a QuikChange Lightning SiteDirected Mutagenesis Kit (Stratagene, La Jolla, CA) following the manufacturer instructions and confirmed by DNA sequence analysis.

\section{Subcellular fractionation}

Subcellular fractions were isolated as previously described [45] with modifications. Briefly, differentiated adipocytes were washed in buffer 1 (100 mM sucrose, 1 mM EGTA, $20 \mathrm{mM}$ MOPS, $\mathrm{pH}$ 7.4) and resuspended in buffer 2 (100 mM sucrose, $1 \mathrm{mM}$ EGTA, $20 \mathrm{mM}$ MOPS, 1\% Triton $\mathrm{X}-100,5 \%$ Percoll, $0.01 \%$ digitonin, $2 \mathrm{mM}$ sodium orthovanadate, $10 \mathrm{mM}$ aprotinin, $10 \mathrm{mM}$ pepstatin $\mathrm{A}$, $10 \mathrm{mM}$ leupeptin, $25 \mathrm{mM}$ calpain inhibitor I and $1 \mathrm{mM}$ PMSF, pH 7.4). Cells were passed through a 30-gauge syringe and incubated for $15 \mathrm{~min}$ on ice, unbroken cells, mitochondria and nuclei were pelleted by centrifugation at $15,000 \mathrm{~g}$. The supernatant was centrifuged at $100,000 \mathrm{~g}$ for $1 \mathrm{~h}$. The resulting supernatant and pellet were designated as the cytosol and membrane fractions, respectively and membrane fractions were resuspended in RIPA buffer.

\section{Deoxy-glucose uptake assay}

Glucose uptake was determined as previously described [31]. Briefly, differentiated 3T3-L1 adipocytes were treated with insulin for 30 minutes after which 2-deoxy- $\left[{ }^{3} \mathrm{H}\right]$ glucose $(0.5 \mu \mathrm{Ci} / \mathrm{ml}$, final concentration) was added for additional 3 minutes. The incorporated radioactivity was quantitated using liquid scintillation counting.

\section{Statistical analyses}

Data are expressed as means \pm standard error of the mean (SEM). Statistical analyses were performed using 
JMP program (SAS Institute). Comparisons between groups were performed using unpaired two-tailed Student's $t$-test. A symbol (such as *) indicates $P \leq 0.05$, whereas a duplicate symbol (such as ${ }^{* *}$ ) indicates $P \leq 0.01$.

\section{Abbreviations}

PTP1B: Protein-tyrosine phosphatase 1B; Munc18c: Mammalian homolog of Unc-18c; SNARE: Soluble N-ethylmaleimide-sensitive factor attachment protein receptor; SNAP32: Synaptosomal-associated protein; VAMP2: Vesicleassociated membrane protein 2 .

\section{Competing interests}

The authors declared that they have no competing interests.

\section{Authors' contributions}

JB: performed research and analyzed data. AB: designed and performed research, analyzed data and revised the manuscript. NN: performed research and revised the manuscript. KM: performed research. FGH: designed research, analyzed data and wrote the manuscript. All authors read and approved the final manuscript.

\section{Acknowledgements}

PTP1B floxed mice were kindly provided by Dr. Benjamin Neel (OCl) and Adiponectin-Cre mice by Dr. Evan Rosen (BIDMC/Harvard University). This work was supported by research grant from the JDRF (1-2009-337) and NIH grants R56DK084317 and R01DK090492 to F.G.H. J.B. is supported by a fellowship from the Training Program in Biomolecular Technology T32GM008799.

\section{Author details}

${ }^{1}$ Nutrition Department, University of California Davis, One Shields Ave, 3135 Meyer Hall, Davis, CA 95616, USA. ${ }^{2}$ Department of Internal Medicine, University of California Davis, Sacramento, CA 95817, USA. ${ }^{3}$ Comprehensive Cancer Center, University of California Davis, Sacramento, CA 95817, USA.

Received: 10 June 2013 Accepted: 6 August 2013

Published: 12 August 2013

\section{References}

1. Holman GD, Sandoval IV: Moving the insulin-regulated glucose transporter GLUT4 into and out of storage. Trends Cell Biol 2001, 11:173-179.

2. Bryant NJ, Govers R, James DE: Regulated transport of the glucose transporter GLUT4. Nat Rev Mol Cell Biol 2002, 3:267-277.

3. Hong W: SNAREs and traffic. Biochim Biophys Acta 2005, 1744:493-517.

4. Weber T, Zemelman BV, McNew JA, Westermann B, Gmachl M, Parlati F, Sollner TH, Rothman JE: SNAREpins: minimal machinery for membrane fusion. Cell 1998, 92:759-772.

5. Cheatham B, Volchuk A, Kahn CR, Wang L, Rhodes CJ, Klip A: Insulinstimulated translocation of GLUT4 glucose transporters requires SNAREcomplex proteins. Proc Natl Acad Sci USA 1996, 93:15169-15173.

6. Halachmi N, Lev Z: The Sec1 family: a novel family of proteins involved in synaptic transmission and general secretion. J Neurochem 1996, 66:889-897.

7. Tellam JT, McIntosh S, James DE: Molecular identification of two novel Munc-18 isoforms expressed in non-neuronal tissues. J Biol Chem 1995, 270:5857-5863.

8. Hata Y, Slaughter CA, Sudhof TC: Synaptic vesicle fusion complex contains unc-18 homologue bound to syntaxin. Nature 1993, 366:347-351.

9. Pevsner J, Hsu SC, Scheller RH: n-Sec1: a neural-specific syntaxin-binding protein. Proc Natl Acad Sci USA 1994, 91:1445-1449.

10. Timmers KI, Clark AE, Omatsu-Kanbe M, Whiteheart SW, Bennett MK, Holman GD, Cushman SW: Identification of SNAP receptors in rat adipose cell membrane fractions and in SNARE complexes coimmunoprecipitated with epitope-tagged N-ethylmaleimide-sensitive fusion protein. Biochem J 1996, 320(Pt 2):429-436.

11. Thurmond DC, Ceresa BP, Okada S, Elmendorf JS, Coker K, Pessin JE: Regulation of insulin-stimulated GLUT4 translocation by Munc18c in 3T3L1 adipocytes. J Biol Chem 1998, 273:33876-33883.
12. Tellam JT, Macaulay SL, Mclntosh S, Hewish DR, Ward CW, James DE: Characterization of Munc-18c and syntaxin-4 in 3T3-L1 adipocytes. Putative role in insulin-dependent movement of GLUT-4. J Biol Chem 1997, 272:6179-6186.

13. Tamori Y, Kawanishi M, Niki T, Shinoda H, Araki S, Okazawa H, Kasuga M: Inhibition of insulin-induced GLUT4 translocation by Munc18c through interaction with syntaxin4 in 3T3-L1 adipocytes. J Biol Chem 1998, 273:19740-19746.

14. Kanda H, Tamori Y, Shinoda H, Yoshikawa M, Sakaue M, Udagawa J, Otani H, Tashiro F, Miyazaki J, Kasuga M: Adipocytes from Munc18c-null mice show increased sensitivity to insulin-stimulated GLUT4 externalization. J Clin Invest 2005, 115:291-301.

15. Aran V, Bryant NJ, Gould GW: Tyrosine phosphorylation of Munc18c on residue 521 abrogates binding to Syntaxin 4. BMC Biochem 2011, 12:19.

16. Jewell JL, Oh E, Ramalingam L, Kalwat MA, Tagliabracci VS, Tackett L, Elmendorf JS, Thurmond DC: Munc18c phosphorylation by the insulin receptor links cell signaling directly to SNARE exocytosis. J Cell Biol 2011 , 193:185-199.

17. Frangioni JV, Beahm PH, Shifrin V, Jost CA, Neel BG: The nontransmembrane tyrosine phosphatase PTP-1B localizes to the endoplasmic reticulum via its 35 amino acid C-terminal sequence. Cell 1992, 68:545-560.

18. Woodford-Thomas TA, Rhodes JD, Dixon JE: Expression of a protein tyrosine phosphatase in normal and v-src-transformed mouse 3T3 fibroblasts. J Cell Biol 1992, 117:401-414.

19. Haj FG, Verveer PJ, Squire A, Neel BG, Bastiaens PI: Imaging sites of receptor dephosphorylation by PTP1B on the surface of the endoplasmic reticulum. Science 2002, 295:1708-1711.

20. Elchebly M, Payette P, Michaliszyn E, Cromlish W, Collins S, Loy AL, Normandin D, Cheng A, Himms-Hagen J, Chan CC, et al: Increased insulin sensitivity and obesity resistance in mice lacking the protein tyrosine phosphatase-1B gene. Science 1999, 283:1544-1548.

21. Klaman LD, Boss O, Peroni OD, Kim JK, Martino JL, Zabolotny JM, Moghal N, Lubkin M, Kim YB, Sharpe AH, et al: Increased energy expenditure, decreased adiposity, and tissue-specific insulin sensitivity in proteintyrosine phosphatase 1B-deficient mice. Mol Cell Biol 2000, 20:5479-5489.

22. Delibegovic M, Bence KK, Mody N, Hong EG, Ko HJ, Kim JK, Kahn BB, Neel BG: Improved glucose homeostasis in mice with muscle-specific deletion of protein-tyrosine phosphatase 1B. Mol Cell Biol 2007, 27:7727-7734.

23. Haj FG, Zabolotny JM, Kim YB, Kahn BB, Neel BG: Liver-specific proteintyrosine phosphatase $1 \mathrm{~B}$ (PTP1B) re-expression alters glucose homeostasis of PTP1B-/-mice. J Biol Chem 2005, 280:15038-15046.

24. Delibegovic M, Zimmer D, Kauffman C, Rak K, Hong EG, Cho YR, Kim JK, Kahn BB, Neel BG, Bence KK: Liver-Specific Deletion of Protein-Tyrosine Phosphatase 1B (PTP1B) Improves Metabolic Syndrome and Attenuates Diet-Induced ER Stress. Diabetes 2008, 58:590-599.

25. Bence KK, Delibegovic M, Xue B, Gorgun CZ, Hotamisligil GS, Neel BG, Kahn BB: Neuronal PTP1B regulates body weight, adiposity and leptin action. Nat Med 2006, 12:917-924.

26. Owen C, Czopek A, Agouni A, Grant L, Judson R, Lees EK, Mcllroy GD, Goransson O, Welch A, Bence KK, et al: Adipocyte-specific protein tyrosine phosphatase $1 \mathrm{~B}$ deletion increases lipogenesis, adipocyte cell size and is a minor regulator of glucose homeostasis. PLoS One 2012, 7:e32700.

27. Rosen ED, Spiegelman BM: Adipocytes as regulators of energy balance and glucose homeostasis. Nature 2006, 444:847-853.

28. Farmer SR: Molecular determinants of brown adipocyte formation and function. Genes Dev 2008, 22:1269-1275.

29. Enerback S: Human brown adipose tissue. Cell Metab 2010, 11:248-252.

30. Bettaieb A, Bakke J, Nagata N, Matsuo K, Xi Y, Liu S, Aboubechara D, Melhem R, Stanhope K, Cummings B, et al: Protein-tyrosine phosphatase $1 \mathrm{~B}$ regulates pyruvate kinase $\mathrm{M} 2$ tyrosine phosphorylation. $\mathrm{J}$ Biol Chem 2013, 288:17360-17371.

31. Matsuo K, Bettaieb A, Nagata N, Matsuo I, Keilhack H, Haj FG: Regulation of brown fat adipogenesis by protein tyrosine phosphatase 1B. PLoS One 2011, 6:e16446.

32. Flint AJ, Tiganis T, Barford D, Tonks NK: Development of "substratetrapping" mutants to identify physiological substrates of protein tyrosine phosphatases. Proc Natl Acad Sci USA 1997, 94:1680-1685.

33. Oh E, Thurmond DC: The stimulus-induced tyrosine phosphorylation of Munc18c facilitates vesicle exocytosis. J Biol Chem 2006, 281:17624-17634.

34. Umahara M, Okada S, Yamada E, Saito T, Ohshima K, Hashimoto K, Yamada M, Shimizu H, Pessin JE, Mori M: Tyrosine phosphorylation of Munc18c 
regulates platelet-derived growth factor-stimulated glucose transporter 4 translocation in 3T3L1 adipocytes. Endocrinology 2008, 149:40-49.

35. Zhang ZY, Maclean D, McNamara DJ, Sawyer TK, Dixon JE: Protein tyrosine phosphatase substrate specificity: size and phosphotyrosine positioning requirements in peptide substrates. Biochemistry 1994, 33:2285-2290.

36. Haj FG, Markova B, Klaman LD, Bohmer FD, Neel BG: Regulation of receptor tyrosine kinase signaling by protein tyrosine phosphatase-1B. J Biol Chem 2003, 278:739-744.

37. Stuible M, Dube N, Tremblay ML: PTP1B regulates cortactin tyrosine phosphorylation by targeting Tyr446. J Biol Chem 2008, 283:15740-15746.

38. Bettaieb A, Matsuo K, Matsuo I, Wang S, Melhem R, Koromilas AE, Haj FG: Protein tyrosine phosphatase 1B deficiency potentiates PERK/elF2alpha signaling in brown adipocytes. PLoS One 2012, 7:e34412.

39. Salmeen A, Andersen JN, Myers MP, Tonks NK, Barford D: Molecular basis for the dephosphorylation of the activation segment of the insulin receptor by protein tyrosine phosphatase 1B. Mol Cell 2000, 6:1401-1412.

40. Huyer G, Liu S, Kelly J, Moffat J, Payette P, Kennedy B, Tsaprailis G, Gresser MJ, Ramachandran C: Mechanism of inhibition of protein-tyrosine phosphatases by vanadate and pervanadate. J Biol Chem 1997, 272:843-851.

41. Garrido-Sanchez L, Escote X, Coin-Araguez L, Fernandez-Garcia JC, El Bekay R, Vendrell J, Garcia-Fuentes E, Tinahones FJ: Munc18c in adipose tissue is downregulated in obesity and is associated with insulin. PLoS One 2013, 8:e63937.

42. Bergman BC, Cornier MA, Horton TJ, Bessesen DH, Eckel RH: Skeletal muscle munc18c and syntaxin 4 in human obesity. Nutr Metab (Lond) 2008, 5:21.

43. Meng TC, Buckley DA, Galic S, Tiganis T, Tonks NK: Regulation of insulin signaling through reversible oxidation of the protein-tyrosine phosphatases TC45 and PTP1B. J Biol Chem 2004, 279:37716-37725.

44. Bettaieb A, Liu S, Xi Y, Nagata N, Matsuo K, Matsuo I, Chahed S, Bakke J, Keilhack H, Tiganis T, Haj FG: Differential regulation of endoplasmic reticulum stress by protein tyrosine phosphatase $1 \mathrm{~B}$ and $\mathrm{T}$ cell protein tyrosine phosphatase. J Biol Chem 2011, 286:9225-9235.

45. Samali A, Cai J, Zhivotovsky B, Jones DP, Orrenius S: Presence of a pre-apoptotic complex of pro-caspase-3, Hsp60 and Hsp10 in the mitochondrial fraction of jurkat cells. Embo J 1999, 18:2040-2048.

46. Stockli J, Fazakerley DJ, James DE: GLUT4 exocytosis. J Cell Sci 2011, 124:4147-4159.

doi:10.1186/1478-811X-11-57

Cite this article as: Bakke et al:: Regulation of the SNARE-interacting protein Munc18c tyrosine phosphorylation in adipocytes by proteintyrosine phosphatase 1B. Cell Communication and Signaling 2013 11:57.

\section{Submit your next manuscript to BioMed Central and take full advantage of:}

- Convenient online submission

- Thorough peer review

- No space constraints or color figure charges

- Immediate publication on acceptance

- Inclusion in PubMed, CAS, Scopus and Google Scholar

- Research which is freely available for redistribution 